\title{
TRANSPORTE E DISTRIBUIÇÃO DE POTÁSSIO ATENUAM OS EFEITOS TÓXICOS DO SÓDIO EM PLANTAS JOVENS DE PINHÃO-MANSO(1)
}

\author{
Cicera Raquel Fernandes Rodrigues ${ }^{(2)}$, Joaquim Albenisio Gomes \\ Silveira ${ }^{(3)}$ Evandro Nascimento Silva ${ }^{(4)}$, Antônia Tathiana Batista \\ Dutra $^{(5)}$ \& Ricardo Almeida Viégas ${ }^{(6)}$
}

\begin{abstract}
RESUMO
Muitos estudos têm evidenciado o papel do $\mathrm{K}$ em atenuar os efeitos causados pelo excesso de Na em plantas. Contudo os mecanismos de interação entre estes dois íons a nível de planta inteira ainda não estão bem compreendidos. Este trabalho foi realizado com o objetivo de caracterizar mecanismos fisiológicos envolvidos na interação entre K e Na em plantas jovens de pinhão-manso (Jatropha curcas) expostas a diferentes concentrações desses íons. $O$ estudo foi conduzido em casa de vegetação em delineamento experimental inteiramente casualizado com esquema fatorial $2 \times 2$, envolvendo combinações de duas concentrações de $\mathrm{K}$ e Na com cinco repetições, em solução nutritiva, perfazendo os seguintes tratamentos: $\mathrm{K}_{0} \mathrm{Na}_{0}$ (ausência de $\mathrm{K}$ e de $\mathrm{Na}$ ), $\mathrm{K}_{0} \mathrm{Na}_{1}\left(0 \mathrm{mmol} \mathrm{L}{ }^{-1}\right.$ de $\mathrm{K}$ e $50 \mathrm{mmol} \mathrm{L}^{-1}$ de $\mathrm{Na}) ; \mathrm{K}_{1} \mathrm{Na}_{0}\left(10 \mathrm{mmol} \mathrm{L}^{-1}\right.$ de $\mathrm{K}$ e $0 \mathrm{mmol} \mathrm{L}^{-1}$ de $\left.\mathrm{Na}\right) ; \mathrm{K}_{1} \mathrm{Na}_{1}\left(10 \mathrm{mmol} \mathrm{L}^{-1}\right.$ de $\mathrm{K}$ e $50 \mathrm{mmol} \mathrm{\textrm {L } ^ { - 1 }}$ de $\mathrm{Na}$ ). Os íons $\mathrm{K}$ e $\mathrm{Na}$ apresentaram forte antagonismo em termos de taxas de transporte em caule, pecíolos e folhas. Quando a concentração de $\mathrm{K}$ externo foi ausente, as plantas de pinhão-manso apresentaram elevada taxa de transporte de Na para as folhas, fato que contribuiu para sua acumulação excessiva na parte aérea, induzindo sintomas visuais de toxidez. Inversamente, a presença de níveis adequados de $\mathrm{K}$ no meio externo foi capaz de atenuar a acumulação excessiva de Na nas diversas partes da planta, pela diminuição do fluxo de Na no xilema. Dessa forma, concentrações adequadas de $\mathrm{K}$ nas raízes podem mitigar os efeitos adversos do excesso de $\mathrm{Na}$ e reduzir seu conteúdo em tecidos de pinhão-manso.
\end{abstract}

Termos de indexação: Jatropha curcas L., absorção, estresse salino, nutrição mineral.

\footnotetext{
(1) Parte da Tese de Doutorado do primeiro autor. Recebido para publicação em 24 de dezembro de 2010 e aprovado em 19 de outubro de 2011.

(2) Doutora em Bioquímica, UFC. Bolsista PNPD. E-mail: quelfer09@gmail.com

(3) Professor do Departamento de Bioquímica e Biologia Molecular, UFC. E-mail: silveira@ufc.br

(4) Doutor em Bioquímica, UFC. Bolsista PNPD. E-mail: evandrons@oi.com.br

(5) Doutoranda em Bioquímica-UFC. E-mail: tathianadutrabioq@gmail.com

(6) Professor do Departamento de Engenharia Florestal, UFCG. E-mail: raviegas@uol.com.br
} 


\title{
SUMMARY: POTASSIUMTRANSPORT AND PARTITIONING ALLEVIATES TOXIC EFFECTS OF SODIUM ON YOUNG PHYSIC NUT PLANTS
}

\begin{abstract}
A number of studies have pointed out how potassium can alleviate the effects of sodium toxicity on plants. However, the mechanisms of interaction between these two ions at the whole plant level are poorly understood so far. This study assessed some physiological mechanisms involved with the K-Na interaction in Jatropha curcas seedlings exposed to salinity. The experiment was carried out in a completely randomized, $2 \times 2$ factorial design (two Na and $K$ levels in nutrient solution, with five replications). The plants were exposed to the following treatments: $K_{0} N a_{0}$ (absence of both $\mathrm{Na}$ and $\left.\mathrm{K}\right), \mathrm{K}_{0} \mathrm{Na} \mathrm{a}_{1}\left(0 \mathrm{mmol} \mathrm{L^{-1 }} \mathrm{K}\right.$ and $50 \mathrm{mmol} \mathrm{L} \mathrm{ma}^{-1} \mathrm{Na}$ ), $K_{1} \mathrm{Na}_{0}\left(10 \mathrm{mmol} \mathrm{L}^{-1} \mathrm{~K}\right.$ and $\left.0 \mathrm{mmol} \mathrm{L} \mathrm{L}^{-1} \mathrm{Na}\right)$ and $\mathrm{K}_{1} \mathrm{Na}_{1}\left(10 \mathrm{mmol} \mathrm{L}^{-1} \mathrm{Kand} 50 \mathrm{mmol} \mathrm{L}-1 \mathrm{Na}\right)$. After the test period, the results showed a strong antagonistic interaction in terms of $K$ and Na transport rates in roots, stems and leaves. Without $[K]_{\text {ext }}$ in the nutrient solution, the Na transport rate in physic nut leaves was high, contributing to an excessive accumulation of this ion in the shoot and inducing toxicity symptoms in leaves. Conversely, the presence of adequate Klevels alleviated the excessive accumulation of sodium in various plant parts, causing a decrease in the xylem Na flux rate. These data suggest that $[K]_{\text {ext }}$ can mitigate the adverse effects of sodium excess and reduce sodium contents in Jatropha curcas tissues.
\end{abstract}

Index terms: Jatropha curcas L, ion uptake, salt stress, nutrition.

\section{INTRODUÇÃO}

O pinhão-manso (Jatropha curcas L.) é uma espécie originada provavelmente das Américas e amplamente cultivada em regiões áridas e semiáridas (Silva et al., 2009a). Essa espécie apresenta enorme potencial como produtora de bioenergia em vários países (Behera et al., 2010). Além disso, acrescenta-se o fato de o pinhão-manso ser resistente às condições adversas de solo e clima, como baixa pluviosidade e temperaturas elevadas (Francis et al., 2005). Entretanto, apesar de ser uma cultura promissora, pouco se conhece sobre os aspectos nutricionais da espécie sob condições de salinidade. Adicionado a isso, alguns autores (Saturnino et al., 2005) relatam que os graves problemas causados pela irrigação dessa cultura no Nordeste brasileiro, gerando salinização dos solos, poderão progressivamente limitar sua produtividade.

Os prejuízos causados pela salinidade elevada dos solos têm sido atribuídos aos efeitos tóxicos de Na sobre o metabolismo das plantas. Assim, o excesso de $\mathrm{Na}$ no solo causa diminuição nos níveis de $\mathrm{K}$ no solo e na planta, especialmente nas raízes (Alves et al., 2008). Esse efeito pode ser devido à ação combinada de redução no influxo e aumento no efluxo de K (Ashley et al., 2006; Apse \& Blumwald, 2007). A interação entre Na e K ocorre no transporte da membrana plasmática, envolvendo transportadores e canais de K (Buschmann et al., 2000; Voigt et al., 2009).

$\mathrm{O}$ mecanismo de interação entre $\mathrm{Na}$ e $\mathrm{K}$ ainda não é totalmente esclarecido, porém as similaridades físico-químicas entre eles são preponderantes para esse processo (Maathius \& Amtmann, 1999). Alta concentração de $\mathrm{Na}$, especialmente nos solos sódicos, aliada à baixa concentração de $\mathrm{K}$, poderá aumentar o transporte de $\mathrm{Na}$, causando carência de $\mathrm{K}$ na planta (Giert \& Maser, 2007). Por outro lado, evidências experimentais têm mostrado que níveis adequados de $\mathrm{K}$ no meio externo contribuem para atenuar a absorção e os efeitos tóxicos do $\mathrm{Na}$ nas plantas (Maathius \& Amtmann, 1999; Munns, 2005). Dessa maneira, uma nutrição adequada em $\mathrm{K}$ poderá favorecer o crescimento de plantas sob condições de salinidade, por meio de uma homeostase $\mathrm{K} / \mathrm{Na}$ mais favorável (Munns, 2002; Zhu, 2003; Munns \& Tester, 2008).

As plantas podem promover homeostase K/ $\mathrm{Na}$ favorável por meio de diversos mecanismos, envolvendo absorção, transporte no xilema, partição entre as partes da planta e compartimentalização entre citosol e vacúolos (Maathius \& Amtmann, 1999; Mengel \& Kirby, 2001; Zhu, 2003). As estratégias para manter níveis adequados de $\mathrm{Ke}$ $\mathrm{Na}$ no citosol variam amplamente entre espécies e cultivares, e esse fator (relação $\mathrm{K} / \mathrm{Na}$ ) tem sido utilizado como marcador fisiológico na seleção de plantas mais resistentes à salinidade (Flowers, 2004; Ashley et al., 2006; Munns \& Tester, 2008). Nesse contexto, os mecanismos de transporte de $\mathrm{Na}$ e $\mathrm{K}$ exercem papel central na homeostase iônica e na resistência ao estresse salino, sobretudo em plantas cultivadas sob baixo nível de $\mathrm{K}$ e em solos salinos (Apse \& Blumwald, 2007).

Resultados anteriores têm mostrado que plantas jovens de pinhão-manso apresentam concentrações muito elevadas de $\mathrm{K}$ nas folhas e que, na presença de teores relativamente baixos 
de Na na solução nutritiva $\left(50 \mathrm{mmol} \mathrm{L}^{-1}\right)$, os níveis de $\mathrm{K}$ foram reduzidos quase 10 vezes (Silva et al., 2009a). Essa observação sugere dois aspectos fisiológicos importantes: a espécie deve ser muito exigente em K; e deve existir intenso antagonismo entre os dois íons (interação do tipo duplamente recíproca). Entretanto, são necessários mais estudos envolvendo a interação entre $\mathrm{Ke} \mathrm{Na}$, nas plantas em geral, particularmente envolvendo o transporte e a distribuição na planta inteira, para que se esclareça melhor a interação entre esse dois íons.

Dessa maneira, o objetivo deste trabalho foi compreender mecanismos da interação entre $\mathrm{K}$ e Na, considerando o transporte e a partição na planta, visando avaliar o papel protetor do K sobre a acumulação de $\mathrm{Na}$, assim como o efeito negativo do excesso de $\mathrm{Na}$ na nutrição potássica.

\section{MATERIAL E MÉTODOS}

\section{Material vegetal e condições experimentais}

O experimento foi conduzido em casa de vegetação pertencente à Universidade Federal do Ceará, Fortaleza, CE $\left(3^{\circ} 44^{\prime} \mathrm{S}\right.$ e $\left.38^{\circ} 33^{\prime} \mathrm{W}\right)$. As condições ambientais no interior da casa de vegetação foram: fotoperíodo de $12 \mathrm{~h}$, temperatura mínima de $24^{\circ} \mathrm{C}$, temperatura máxima de $36{ }^{\circ} \mathrm{C}$, temperatura média diária de $29{ }^{\circ} \mathrm{C}$, umidade relativa do ar média de $65 \%$ e radiação fotossinteticamente ativa máxima de aproximadamente $700 \mu \mathrm{mol} \mathrm{m}{ }^{-2} \mathrm{~s}^{-1}$.

Foram utilizadas sementes de pinhão-manso da linhagem FT 2, fornecidas pelo Instituto Fazenda Tamanduá, Santa Terezinha-PB. Sementes previamente selecionadas por tamanho e peso foram germinadas em areia e mantidas oito dias após a semeadura, sendo irrigadas diariamente com água destilada. Em seguida, as plântulas foram transferidas para vasos de 2,0 L (uma planta por vaso), contendo solução de Hoagland \& Arnon (1950) com diluição de $1 / 4$ na primeira semana e $1 / 2$ na segunda semana, com $\mathrm{pH}$ 6,0 ajustado a cada dois dias com $\mathrm{NaOH} 1 \mathrm{~mol} \mathrm{~L}^{-1}$ ou $\mathrm{HCl} 1 \mathrm{~mol} \mathrm{~L}^{-1}$. As soluções foram completamente renovadas a cada semana e mantidas sob aeração forçada. As concentrações de $\mathrm{K}$ na solução nutritiva foram de 1,5 e $3,0 \mathrm{~mol} \mathrm{~L}^{-1}$, na primeira e segunda semanas, respectivamente.

Em seguida, plantas com três semanas de idade (após a semeadura) foram transferidas para novas soluções nutritivas contendo as seguintes concentrações de $\mathrm{K}$ e $\mathrm{Na}$, fornecidos como $\mathrm{KCl}$ e $\mathrm{NaCl}$, perfazendo quatro tratamentos: (1) ausência de $\mathrm{K}$ e de $\mathrm{Na}\left(\mathrm{K}_{0} \mathrm{Na}_{0}\right)$; (2) ausência de $\mathrm{K}$ e presença de $50 \mathrm{mmol} \mathrm{L}^{-1}$ de $\mathrm{Na}\left(\mathrm{K}_{0} \mathrm{Na}_{1}\right)$; (3) $10 \mathrm{mmol} \mathrm{L}^{-1} \mathrm{de}$ $\mathrm{K}$ e ausência de $\mathrm{Na}\left(\mathrm{K}_{1} \mathrm{Na}_{0}\right)$; e (4) $10 \mathrm{mmol} \mathrm{L}^{-1}$ de $\mathrm{K}$ e $50 \mathrm{mmol} \mathrm{L}^{-1}$ de $\mathrm{Na}\left(\mathrm{K}_{1} \mathrm{Na}_{1}\right)$. O tratamento
$\mathrm{K}_{1} \mathrm{Na}_{0}$ foi adotado como referência ou controle. Utilizou-se $\mathrm{KCl}$ e $\mathrm{NaCl}$ como fonte de $\mathrm{K}$ e de $\mathrm{Na}$, respectivamente, dissolvidos na solução de Hoagland \& Arnon (1950) com diluição de $1 / 2$. Ao final de oito dias de tratamento, plantas com oito folhas totalmente expandidas foram coletadas, separadas em diferentes partes (folhas, caules, pecíolos e raízes) e secas em estufa com circulação de $\operatorname{ar}\left(70{ }^{\circ} \mathrm{C}\right.$ por $72 \mathrm{~h}$ ), para as determinações de massa seca e as concentrações de $\mathrm{Na}$ e K.

\section{Determinação das concentrações de sódio e potássio}

As determinações das concentrações de $\mathrm{Na}$ e $\mathrm{K}$ foram realizadas conforme descrito em Silva et al. (2009b). A extração foi feita utilizando $50 \mathrm{mg}$ de material moído com $20 \mathrm{~mL}$ de $\mathrm{H}_{2} \mathrm{O}$ deionizada em banho-maria a $100{ }^{\circ} \mathrm{C}$ por uma hora. O extrato obtido foi centrifugado e seu sobrenadante analisado em fotômetro de chama (Micronal, modelo B462), para as determinações das concentrações de $\mathrm{Na}$ e K a partir de curvas-padrão obtidas com $\mathrm{NaCl}$ e $\mathrm{KCl}$, respectivamente.

\section{Determinação dos fluxos na seiva, taxa de acumulação de Ke Na e seletividade dos fluxos dos íons K e Na em partes da planta}

A coleta da seiva do xilema radicular foi realizada pela técnica de extração de vácuo (Schurr, 1998). Para isso, o caule foi cortado em bisel na altura no colo, a $3 \mathrm{~cm}$ da raiz. As primeiras gotas do exsudado foram descartadas, e as seguintes, coletadas num intervalo de uma hora. As amostras foram armazenadas em microtubos e congeladas a $-20^{\circ} \mathrm{C}$, para determinação das concentrações de $\mathrm{Na}$ e K. Inicialmente, foi determinado o fluxo da seiva do xilema por meio da pesagem do líquido coletado, assumindo uma densidade de 1,0 para a seiva. As concentrações de $\mathrm{K}$ e $\mathrm{Na}$ foram determinadas por fotometria de chama, e o fluxo dos íons na seiva foi expresso em $\mathrm{mmol} \mathrm{kg} \mathrm{h}^{-1}$ de seiva.

As taxas de acumulação de $\mathrm{Na}\left(\mathrm{J}_{\mathrm{Na}}\right)$ e $\mathrm{K}\left(\mathrm{J}_{\mathrm{K}}\right)$ (Equação 1) em folhas, caules, pecíolos e raízes foram calculadas a partir da variação das concentrações de $\mathrm{Na}$ e K (no início e ao final de oito dias de tratamento) e da variação da massa seca das raízes de acordo com equação descrita por Welbank (1962). O tempo inicial correspondeu a um grupo de plantas que foram coletadas no início do tratamento, separadas em diferentes órgãos (folhas, caules, pecíolos e raízes) e secas em estufa com circulação de ar $\left(70{ }^{\circ} \mathrm{C}\right.$ por $72 \mathrm{~h}$ ), para posteriores determinações das concentrações de $\mathrm{Na}$ e K e massa seca total.

$$
\mathrm{J}_{\mathrm{Na}} \text { or } \mathrm{J}_{\mathrm{K}}=\frac{\left(M_{2}-M_{1}\right)}{T_{2}-T_{1}} \times \frac{\ln \left(W_{2}-W_{1}\right)}{W_{2}-W_{1}}
$$

em que $\mathrm{J}_{\mathrm{Na}}$ ou $\mathrm{J}_{\mathrm{K}}$ : $\mathrm{M}_{1}$ e $\mathrm{M}_{2}=$ concentrações de $\mathrm{K}$ e $\mathrm{Na}$ nas diferentes partes da planta no tempo inicial 
$\left(\mathrm{M}_{1}\right)$ e tempo final $\mathrm{M}_{2}$, oito dias; $\mathrm{T}=$ tempo em dias, sendo $\mathrm{T}_{1}$ o tempo inicial e $\mathrm{T}_{2}$ o tempo após oito dias de tratamento. $\mathrm{W}=$ massa seca de raízes, sendo $\mathrm{W}_{1}$ no tempo inicial e $\mathrm{W}_{2}$ massa seca no tempo final. Os resultados de fluxo foram expressos como mmol kg dia ${ }^{-1}$ de massa seca de raiz.

A seletividade de $\mathrm{K}-\mathrm{Na}$ dos fluxos de íons foi descrita (Equação 2) pela relação de seletividade fornecida por Jeschke \& Stelter (1983):

$$
\mathrm{S}_{\mathrm{K}, \mathrm{Na}}=\frac{J_{K}}{J_{N a}} \mathrm{x} \frac{\left[N a^{+}\right]_{e x t}}{\left[K^{+}\right]_{e x t}}
$$

\section{Taxa de transpiração}

Ao final do período dos tratamentos, foram realizadas leituras de transpiração em folhas totalmente expandidas do terço médio das plantas, utilizando um analisador de gás no infravermelho (IRGA, mod. LCA-2, ADC, Hoddesdon, UK). As leituras foram feitas na casa de vegetação entre $9 \mathrm{e}$ 10 horas da manhã, em dia de céu claro.

\section{Delineamento experimental}

$\mathrm{O}$ experimento foi conduzido em delineamento inteiramente casualizado, em esquema fatorial $2 \times 2$ (duas doses de $\mathrm{K}$ e duas de $\mathrm{Na}$ ), com cinco repetições, sendo uma planta por vaso representando uma unidade experimental. Os resultados foram submetidos à análise de variância, e as médias, comparadas pelo teste de Tukey $(\mathrm{p}<0,05)$.

\section{RESULTADOS}

Acúmulo de massa seca em diferentes partes, fluxo dos íons na seiva do xilema radicular e transpiração

Ao final dos oito dias de tratamento com as diferentes combinações $\mathrm{K} \times \mathrm{Na}$, plantas de pinhão-manso mostraram diferenças $(p<0,05)$ na acumulação de massa seca em folhas, caules, pecíolos e raízes (Quadro 1). Nos tratamentos com ausência de $\mathrm{K}$ na solução nutritiva $\left(\mathrm{K}_{0} \mathrm{Na}_{0}\right.$ e $\left.\mathrm{K}_{0} \mathrm{Na}_{1}\right)$, a massa seca das folhas foi reduzida por efeito da presença de $\mathrm{Na}$ e, ou, ausência de K. Esse mesmo efeito foi observado nas duas combinações com a presença de um nível elevado de $\mathrm{K}\left(10 \mathrm{mmol} \mathrm{L}^{-1}\right)$ : $\mathrm{K}_{1} \mathrm{Na}_{0}$ e $\mathrm{K}_{1} \mathrm{Na}_{1}$ (Quadro 1). As demais partes da planta (caules, pecíolos e raízes), em se tratando dos efeitos das combinações $\mathrm{K} \times \mathrm{Na}$, mostraram resultados distintos dos observados nas folhas. Nos caules, houve redução de massa seca somente no tratamento com alto nível de $\mathrm{K}$ e presença de $\mathrm{Na}$ $\left(\mathrm{K}_{1} \mathrm{Na}_{1}\right)$. Nos pecíolos, os tratamentos com a presença de $\mathrm{K}$ apresentaram maior massa seca do que aqueles sem $\mathrm{K}$, independentemente da presença ou não do Na. Já nas raízes, não houve diferenças $(p>0,05)$ entre os tratamentos (Quadro 1). É interessante destacar que, nos tratamentos $\mathrm{K}_{0} \mathrm{Na}_{0}$ e $\mathrm{K}_{1} \mathrm{Na}_{1}$, as massas secas das folhas e raízes não se diferenciaram, indicando possível compensação da ausência de $\mathrm{K}$ com a presença do Na (Quadro 1). Todas as comparações entre os tratamentos foram feitas com o tratamento $\mathrm{K}_{1} \mathrm{Na}_{0}$, assumido como controle.

Nesse contexto, é importante observar que, mesmo na ausência de $\mathrm{K}$ durante oito dias, as concentrações desse íon, nas diversas partes das plantas, atingiram níveis adequados desse nutriente (Quadro 2). De fato, nesses tratamentos, as folhas apresentaram concentrações de 2,81 e $2,86 \%$ na base de massa seca, nos tratamentos $\mathrm{K}_{0} \mathrm{Na}_{0}$ e $\mathrm{K}_{0} \mathrm{Na}_{1}$, respectivamente. Com relação ao $\mathrm{Na}$, as maiores concentrações desse íon foram alcançadas nas folhas e no tratamento $\mathrm{K}_{0} \mathrm{Na}_{1}$, que atingiu valores de $3,75 \%$ ou $1.659 \mathrm{mmol} \mathrm{kg}^{-1} \mathrm{MS}$ (Quadro 2). Apesar dessa concentração de Na ter sido elevada, ela acarretou pequenas reduções de massa seca nas diversas partes da planta.

A presença de $10 \mathrm{mmol} \mathrm{L}^{-1}$ de $\mathrm{K}$ na solução nutritiva $\left(\mathrm{K}_{1}\right)$ causou intensa redução no fluxo de $\mathrm{Na}$ na seiva do xilema (tratamentos $\mathrm{K}_{0} \mathrm{Na}_{1}$

Quadro 1. Massa seca de folhas, caules, pecíolos e raízes de pinhão-manso submetido a diferentes concentrações externas de $\mathrm{K}$ e $\mathrm{Na}$ por um período de oito dias

\begin{tabular}{ccccc}
\hline Tratamento & Folhas & Caules & Pecíolos & Raízes \\
\cline { 3 - 5 } & & & & \\
& & & & \\
$\mathrm{K}_{0} \mathrm{Na}_{0}$ & $0,80 \mathrm{~b}$ & $0,47 \mathrm{a}$ & $0,15 \mathrm{~b}$ & $0,28 \mathrm{a}$ \\
$\mathrm{K}_{0} \mathrm{Na}_{1}$ & $0,65 \mathrm{c}$ & $0,46 \mathrm{a}$ & $0,15 \mathrm{~b}$ & $0,29 \mathrm{a}$ \\
$\mathrm{K}_{1} \mathrm{Na}_{0}$ & $0,90 \mathrm{a}$ & $0,48 \mathrm{a}$ & $0,18 \mathrm{a}$ & $0,30 \mathrm{a}$ \\
$\mathrm{K}_{1} \mathrm{Na}_{1}$ & $0,75 \mathrm{~b}$ & $0,37 \mathrm{~b}$ & $0,18 \mathrm{a}$ & $0,28 \mathrm{a}$
\end{tabular}

$\overline{\mathrm{K}_{0}}$ : ausência de potássio; $\mathrm{K}_{1}: 10 \mathrm{mmol} \mathrm{L}{ }^{-1}$ de $\mathrm{K} ; \mathrm{Na}_{0}$ : ausência de sódio; e $\mathrm{Na}_{1}: 50 \mathrm{mmol} \mathrm{L}^{-1}$ de $\mathrm{Na}$ na solução nutritiva. Os valores representam médias de cinco repetições. Médias iguais seguidas de letras minúsculas não denotam diferenças significativas, conforme o teste de Tukey $(\mathrm{p}<0,05)$. 
Quadro 2. Concentrações de Na e K em folhas, caules, pecíolos e raízes de pinhão-manso submetidos a diferentes concentrações externas de $\mathrm{K}$ e $\mathrm{Na}$ por um período de oito dias

\begin{tabular}{|c|c|c|c|c|c|c|c|c|}
\hline \multirow{2}{*}{ Tratamentos } & \multicolumn{4}{|c|}{$\mathbf{K}$} & \multicolumn{4}{|c|}{$\mathrm{Na}$} \\
\hline & Raiz & Folha & Caules & Pecíolo & Raiz & Folha & Caule & Pecíolo \\
\hline & \multicolumn{8}{|c|}{$\mathrm{mmol} \mathrm{kg}{ }^{-1} \mathrm{MS}$} \\
\hline $\mathrm{K}_{0} \mathrm{Na}_{0}$ & $788 \mathrm{cB}$ & $722 \mathrm{cB}$ & $961 \mathrm{cA}$ & $299 \mathrm{bC}$ & $565 \mathrm{cA}$ & $340 \mathrm{~dB}$ & $326 \mathrm{~dB}$ & $282 \mathrm{cC}$ \\
\hline $\mathrm{K}_{0} \mathrm{Na}_{1}$ & $666 \mathrm{~dB}$ & $735 \mathrm{cB}$ & $1064 \mathrm{cA}$ & $194 \mathrm{cC}$ & $1478 \mathrm{aB}$ & $1659 \mathrm{aA}$ & $1637 \mathrm{aA}$ & $753 \mathrm{bC}$ \\
\hline $\mathrm{K}_{1} \mathrm{Na}_{0}$ & $1576 \mathrm{aB}$ & $1837 \mathrm{aA}$ & $1448 \mathrm{a}$ & $649 a$ & $500 \mathrm{cA}$ & $405 \mathrm{cB}$ & $391 \mathrm{cB}$ & $293 \mathrm{cC}$ \\
\hline $\mathrm{K}_{1} \mathrm{Na}_{1}$ & $1320 \mathrm{bA}$ & $1444 \mathrm{bA}$ & $1217 \mathrm{bB}$ & $598 \mathrm{aC}$ & $1282 \mathrm{bA}$ & $1057 \mathrm{bB}$ & $1043 \mathrm{bB}$ & $851 \mathrm{aC}$ \\
\hline
\end{tabular}

$\mathrm{K}_{0}$ : ausência de potássio; $\mathrm{K}_{1}: 10 \mathrm{mmol} \mathrm{L}{ }^{-1}$ de $\mathrm{K} ; \mathrm{Na}_{0}$ : ausência de sódio; e $\mathrm{Na}_{1}$ : $50 \mathrm{mmol} \mathrm{L}^{-1}$ de $\mathrm{Na}$ na solução nutritiva. Os valores representam médias de cinco repetições. Médias iguais seguidas de letras minúsculas (entre tratamentos) e maiúsculas (entre órgãos) não denotam diferenças significativas, conforme o teste de Tukey $(\mathrm{p}<0,05)$.

versus $\mathrm{K}_{1} \mathrm{Na}_{1}$ ) Essa redução foi na ordem de $50 \%$. Diferentemente, a presença de $50 \mathrm{mmol} \mathrm{L}^{-1}$ de $\mathrm{Na}$ causou redução menor (17\%) no fluxo de $\mathrm{K}$ na seiva do xilema (tratamentos $\mathrm{K}_{1} \mathrm{Na}_{0}$ versus $\mathrm{K}_{1} \mathrm{Na}_{1}$ ) (Figura 1a,b), indicando que, a despeito de a concentração de $\mathrm{Na}$ na solução ter sido cinco vezes maior que a de $\mathrm{K}$, este apresentou seletividade maior no xilema, em comparação ao Na. Como esperado, o tratamento controle $\left(\mathrm{K}_{1} \mathrm{Na}_{0}\right)$ apresentou os maiores valores de fluxo de $\mathrm{K}$ e os menores de $\mathrm{Na}$. Os tratamentos na ausência de $\mathrm{K}\left(\mathrm{K}_{0} \mathrm{Na}_{0}\right.$ e $\left.\mathrm{K}_{0} \mathrm{Na}_{1}\right)$ apresentaram menores fluxos de $\mathrm{K}$, comparados ao controle. A presença de $\mathrm{K}$ foi essencial para as taxas de transpiração, as quais foram reduzidas pela presença do $\mathrm{Na}$. Foi observada relação próxima entre as taxas de transpiração e o fluxo de $\mathrm{K}$ no xilema (Figura 1a,c).

\section{Taxas de acumulação de K e Na e seletividade de $\mathrm{K}$ em folhas, caule, pecíolos e raízes}

As taxas de acumulação de $\mathrm{K}$ foram sempre maiores no tratamento $\mathrm{K}_{1} \mathrm{Na}_{0}$ em todas as partes analisadas, sendo essa acumulação reduzida na presença de $\mathrm{Na}$, com exceção dos pecíolos (Figura 2a,c,e,g). Por outro lado, a taxa de acumulação de Na foi maior no tratamento $\mathrm{K}_{0} \mathrm{Na}_{1}$ em todas as partes estudadas (Figura 2b,d,f,h). E importante destacar que as taxas de acumulação do $\mathrm{Na}^{+}$foram maiores que as do $\mathrm{K}$ nos tratamentos com presença de $\mathrm{Na}$ em todas as partes analisadas (Figura 2). A presença de $\mathrm{K}$ na concentração de $10 \mathrm{mmol} \mathrm{L}^{-1}$ causou redução de $52 \%$ no transporte de Na para as folhas (tratamentos $\mathrm{K}_{1} \mathrm{Na}_{1}$ versus $\mathrm{K}_{0} \mathrm{Na}_{1}$ ), ao passo que a presença de $50 \mathrm{mmol} \mathrm{L}^{-1}$ de Na mostrou menor (28\%) influência na taxa líquida de transporte de $\mathrm{K}$ para as folhas (tratamentos $\mathrm{K}_{1} \mathrm{Na}_{1}$ versus $\mathrm{K}_{1} \mathrm{Na}_{0}$ ). Mais uma vez, esses resultados indicam que o $\mathrm{K}$ possuiu maior seletividade nas folhas de pinhão-manso, quando comparado ao Na.
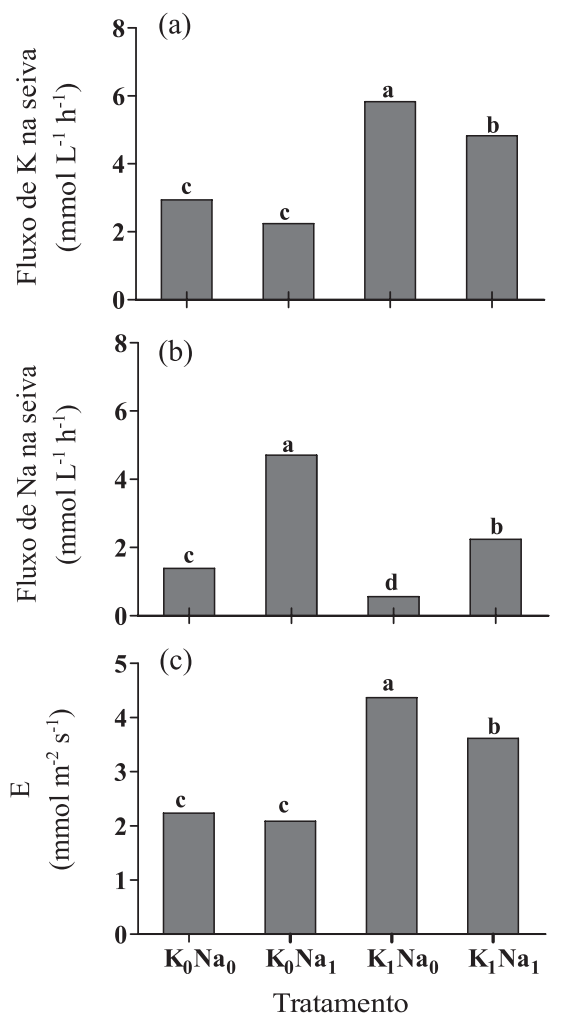

Figura 1. Fluxo de (a) K e (b) Na na seiva de xilema e (c) transpiração em plantas de pinhão-manso submetidas a diferentes concentrações externas de $\mathrm{K}$ e Na por um período de oito dias. $K_{0}$ : ausência de potássio; $K_{1}: 10 \mathrm{mmol} \mathrm{L}^{-1}$ de $K$; $\mathrm{Na}_{0}$ : ausência de $\mathrm{Na}$; e $\mathrm{Na}_{1}: 50 \mathrm{mmol} \mathrm{L}^{-1}$ de $\mathrm{Na}$ na solução nutritiva. Os valores representam médias de cinco repetições. Médias iguais seguidas de letras minúsculas não denotam diferenças significativas, conforme o teste de Tukey $(\mathrm{p}<0,05)$.

No caule, o antagonismo entre os transportes foi evidenciado por reduções semelhantes: a presença de K causou redução de 53 \% no transporte de $\mathrm{Na}$ 
(combinações $\mathrm{K}_{1} \mathrm{Na}_{1}$ versus $\mathrm{K}_{1} \mathrm{Na}_{0}$ ), enquanto a de $\mathrm{Na}$ induziu redução de $41 \%\left(\mathrm{~K}_{1} \mathrm{Na}_{1}\right.$ versus $\left.\mathrm{K}_{0} \mathrm{Na}_{1}\right)$.

Nos pecíolos, as taxas de transporte desses dois íons foram muito menores do que nas folhas e nos caules, devido às baixas concentrações após o período de exposição aos tratamentos. Nesse caso, não houve interação ( $p>0,05)$, ou seja, a presença de um íon não influenciou a taxa de acumulação do outro. Já as raízes mostraram resposta diferencial quando comparada à de folhas, caule e pecíolos. Naquela parte, a presença de K externo causou redução de 31 \% na taxa de transporte de $\mathrm{Na}$ $\left(\mathrm{K}_{1} \mathrm{Na}_{1}\right.$ versus $\mathrm{K}_{0} \mathrm{Na}_{1}$ ), enquanto a presença desse íon reduziu (16\%) o transporte de $\mathrm{K}\left(\mathrm{K}_{1} \mathrm{Na}_{1}\right.$ versus
$\mathrm{K}_{1} \mathrm{Na}_{0}$ ). Em síntese, a despeito de $[\mathrm{K}]_{\text {ext }}$ ter sido cinco vezes menor que $[\mathrm{Na}]_{\text {ext }}$, o primeiro mostrou maior seletividade no transporte para a parte aérea, apesar das menores taxas de transporte apresentadas. Em outras palavras, o K externo foi capaz de reduzir $(p<0,05)$ a taxa de transporte de $\mathrm{Na}$ e, consequentemente, a acumulação de íon salino. Os pecíolos mostraram resposta singular, não apresentando acumulação desses íons, em comparação com as taxas de acumulação e seletividade para estes.

A seletividade de K-Na, com base nos fluxos dos dois íons, mostrou diferenças $(p<0,05)$ entre os tratamentos. Por exemplo, no tratamento $\mathrm{K}_{1} \mathrm{Na}_{1}$
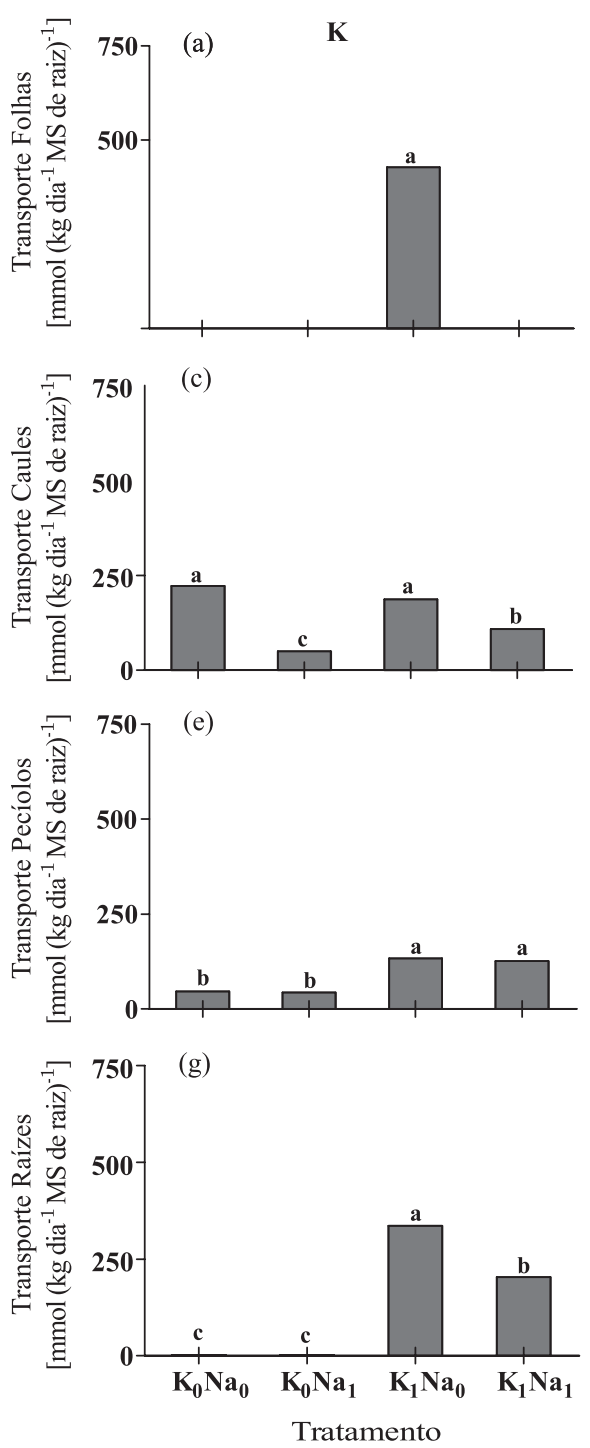

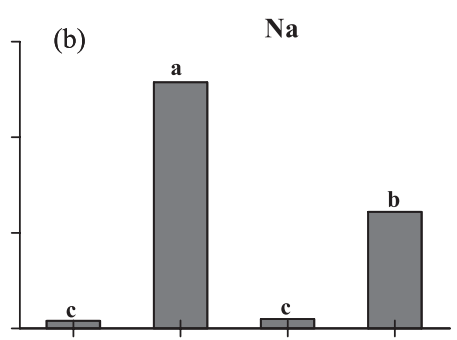

(d)

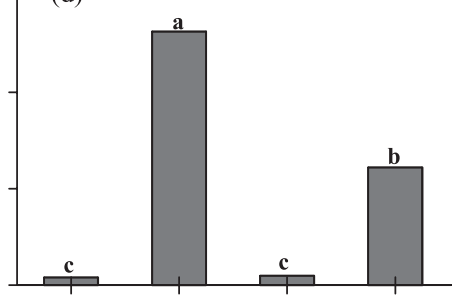

(f)

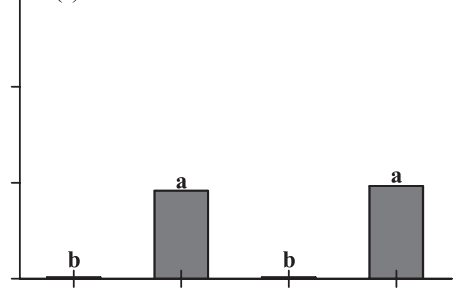

(h)

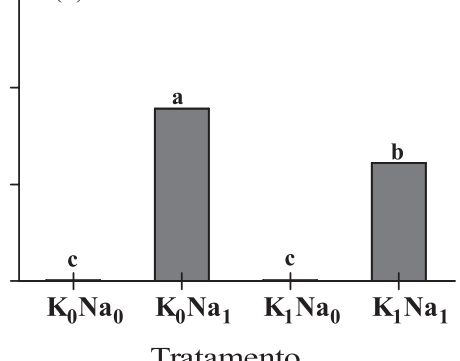

Figura 2. Transporte de K e Na em (a,b) folhas, (c,d) caule, (e,f) pecíolos e (g,h) raízes, respectivamente em plantas de pinhão-manso submetidas a diferentes concentrações externas de $\mathrm{K}$ e Na por um período de oito dias. $K_{0}$ : ausência de potássio; $K_{1}: 10 \mathrm{mmol} \mathrm{L}^{-1}$ de $\mathrm{K}$; $\mathrm{Na}_{0}$ : ausência de sódio; e $\mathrm{Na}_{1}$ : $50 \mathrm{mmol} \mathrm{L}^{-1}$ de Na na solução nutritiva. Os valores representam médias de cinco repetições. Médias iguais seguidas de letras minúsculas não denotam diferenças significativas, conforme o teste de Tukey $(p<0,05)$. 
a seletividade de K-Na foi maior nas folhas $(23,0)$, seguido por caules $(6,1)$, raízes $(5,5)$ e pecíolos $(3,0)$. Similarmente, nos tratamentos $\mathrm{K}_{1} \mathrm{Na}_{0}$ e $\mathrm{K}_{0} \mathrm{Na}_{0}$, a seletividade desses íons também foi maior nas folhas do que nas demais partes Por sua vez, no tratamento $\mathrm{K}_{0} \mathrm{Na}_{1}$ foi observada menor seletividade nas folhas e padrões semelhantes nas outras partes (Figura 3). A seletividade calculada com base na relação entre
$\mathrm{K} / \mathrm{Na}$ por meio da relação molar (concentração), entre os íons nos tecidos de cada parte da planta, mostrou que, comparando as combinações $\mathrm{K}_{1} \mathrm{Na}_{1}$ e $\mathrm{K}_{0} \mathrm{Na}_{1}$, as relações foram reduzidas em $73 \%$ (de $1,16$ para 0,31$), 45 \%(1,16$ para 0,63$), 64 \%(0,70$ para 0,25$), 55 \%(1,02$ para 0,45$)$ e $53 \%(2,15$ para 0,47), em folhas, caules, pecíolos, raízes e xilema, respectivamente (Figura 4).
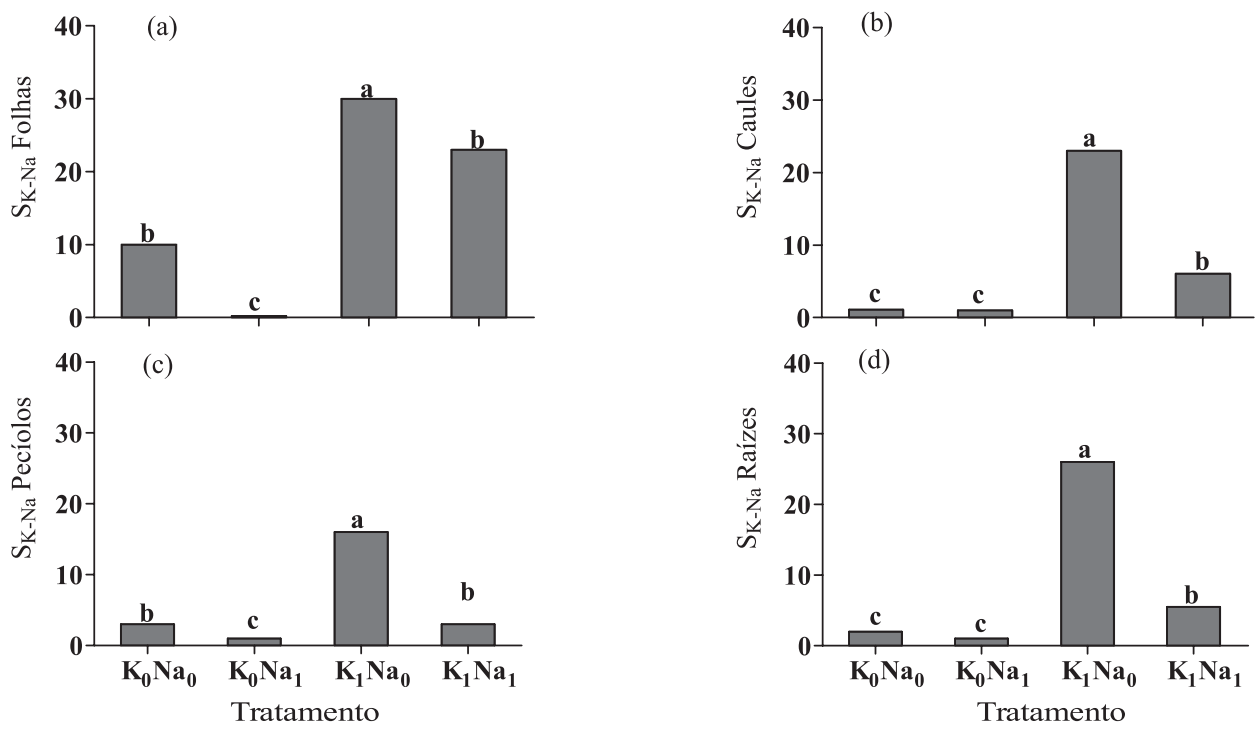

Figura 3. Seletividade de K-Na em (a) folhas, (b) caule, (c) pecíolos e (d) raízes de pinhão-manso submetido a diferentes concentrações externas de $\mathrm{K}$ e Na por um período de oito dias. $\mathrm{K}_{0}$ : ausência de potássio; $\mathrm{K}_{1}: 10 \mathrm{mmol} \mathrm{L}^{-1}$ de $\mathrm{K} ; \mathrm{Na}_{0}$ : ausência de sódio; e $\mathrm{Na}_{1}$ : $50 \mathrm{mmol} \mathrm{L}^{-1}$ de $\mathrm{Na}$ na solução nutritiva. Os valores representam médias de cinco repetições. Médias iguais seguidas de letras minúsculas não denotam diferenças significativas, conforme o teste de Tukey $(p<0,05)$.
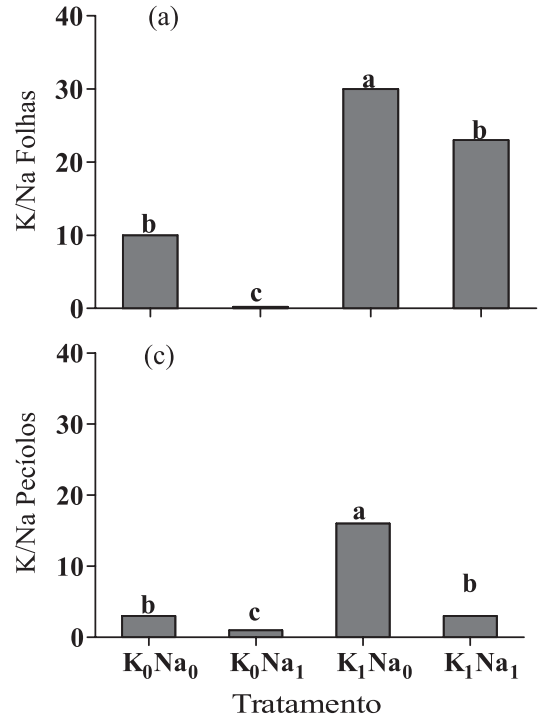
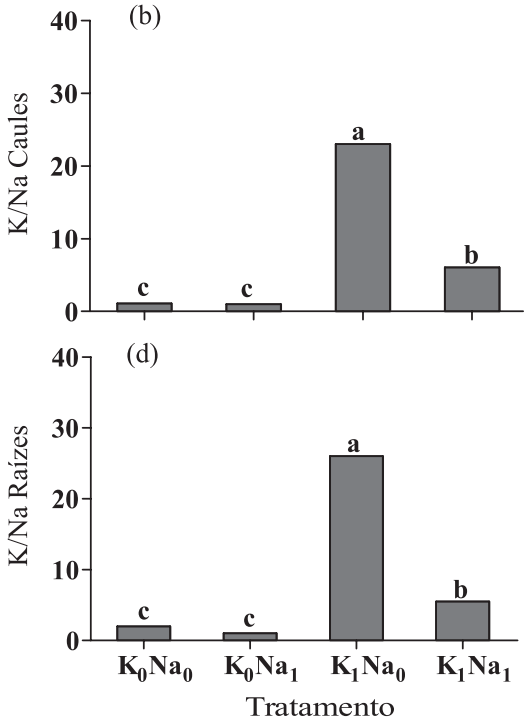

Figura 4. Dados da relação K/Na em (a) folhas, (b) caule, (c) pecíolos e (d) raízes de plantas de pinhãomanso submetidas a diferentes concentrações externas de $\mathrm{K}$ e $\mathrm{Na}$ por um período de oito dias. $\mathrm{K}_{0}$ : ausência de potássio; $\mathrm{K}_{1}: 10 \mathrm{mmol} \mathrm{L}^{-1} \mathrm{de} \mathrm{K} ; \mathrm{Na}_{0}$ : ausência de sódio; e $\mathrm{Na}_{1}$ : $50 \mathrm{mmol} \mathrm{L}^{-1}$ de $\mathrm{Na}$ na solução nutritiva. Os valores representam médias de cinco repetições. Médias iguais seguidas de letras minúsculas não denotam diferenças significativas, conforme o teste de Tukey $(p<0,05)$. 
A presença de concentração elevada de K no meio externo foi capaz de reduzir $(p<0,05)$ as taxas de acumulação de $\mathrm{Na}$, especialmente nas folhas e nos caules. Associado com a maior seletividade de K, esse nutriente foi capaz de atenuar os efeitos tóxicos causados pelo $\mathrm{Na}$ (Figura 5).

\section{DISCUSSÃO}

A despeito do forte antagonismo entre $\mathrm{K} \mathrm{e}$ $\mathrm{Na}$ nas taxas de acumulação desses íons nas diversas partes e no fluxo na seiva do xilema, eles atingiram concentrações apreciáveis nas diversas partes vegetativas de plantas jovens de pinhão-manso, mesmo sob competição de ambos. A espécie possui grande afinidade por esses íons, conforme demonstrado previamente por Silva et al. (2009a), podendo, portanto, ser classificada como concentradora desses íons, especialmente nas folhas. O K presente no meio externo foi capaz de reduzir as taxas de acumulação do $\mathrm{Na}$ na parte aérea, reduzindo, com isso, a sua toxidez. A maioria das espécies vegetais responde de maneira similar em termos de antagonismo $\mathrm{K}-\mathrm{Na}$; esse assunto tem sido amplamente relatado (Maathius \& Amtmann, 1999; Zhu, 2003).

Espécies ou cultivares com capacidade para excluir o $\mathrm{Na}$ de partes vitais da célula, como o citosol e organelas (exceção dos vacúolos), mantendo uma homeostase favorável, são mais aptas a enfrentar a salinidade, sobretudo em solos sódicos e salinosódicos (Munns, 2002, 2005; Munns \& Tester, 2008). Essa característica apresenta grande variabilidade genética e pode ser explorada no desenvolvimento de cultivares resistentes ao estresse salino (Flowers, 2004). A base molecular e fisiológica das interações $K$ vs. $\mathrm{Na}$ sob condições de excesso de $\mathrm{NaCl}$ é complexa e ainda pouco compreendida (Buschmann et al., 2000; Rubio et al., 2003); alguns dos mecanismos que controlam essa interação ocorrem no transporte via membrana plasmática, envolvendo canais e transportadores de K (Ebert et al., 2002; Alves et al., 2008; Voigt et al., 2009). Esse primeiro controle é exercido nas raízes e envolve processos de influxo
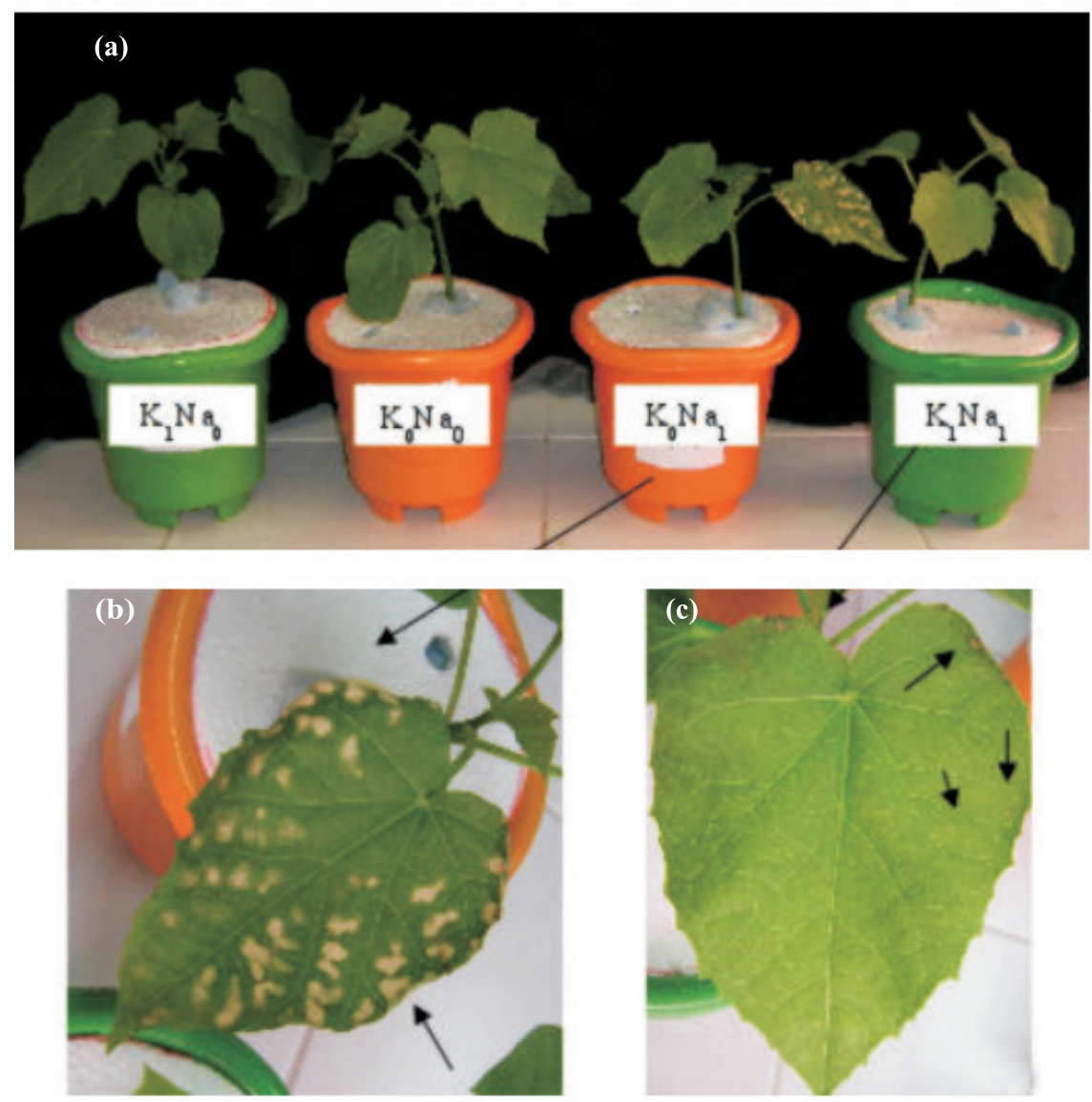

Figura 5. (a) Crescimento das plantas nos diferentes tratamentos. $K_{0}$ : ausência de potássio; $K_{1}: 10$ mmol $L^{-1}$ de $\mathrm{K}$; $\mathrm{Na}_{0}$ : ausência de sódio; e $\mathrm{Na}_{1}$ : $50 \mathrm{mmol} \mathrm{L}^{-1}$ de $\mathrm{Na}$ na solução nutritiva; (b) e (c), sintomas de toxidez em folhas de plantas jovens de pinhão-manso causados por excesso de sais por um período de oito dias. 
e efluxo associados com os sistemas de alta e baixa afinidade (Ebert et al., 2002; Essah et al., 2003). A despeito de essa interação K vs. Na ainda não estar totalmente esclarecida, as evidências apontam que o transporte de $\mathrm{Na}$ ocorre principalmente através do sistema de baixa afinidade de $\mathrm{K}$, envolvendo canais e transportadores de $\mathrm{K}$, além de canais não seletivos de cátions (Buschmann et al., 2000; Ferreira et al., 2001; Essah et al., 2003; Rubio et al., 2003).

A presença de concentração elevada de K causou intenso decréscimo no fluxo de Na na seiva do xilema radicular (Figura 1A). Esse tipo de interação é bastante favorável no sentido de controlar o fluxo desse íon para a parte aérea das plantas. De fato, na presença de $K$, as taxas de acumulação de $\mathrm{Na}$ nas folhas foram diminuídas, indicando que a redução no carregamento desse íon no xilema radicular, exercida pelo $\mathrm{K}$, foi essencial no processo global de distribuição de $\mathrm{Na}$ na parte aérea. A passagem de $\mathrm{Na}$ da raiz para os vasos xilemáticos nas plantas, através das células do parênquima, envolve transportadores e canais seletivos de $\mathrm{K}$ (Munns \& Tester, 2008). Esse passo é considerado essencial para limitar o fluxo de $\mathrm{Na}$ da parte aérea e contribui decisivamente para maior tolerância ao estresse salino em algumas espécies, como ocorre, por exemplo, em cevada (Munns, 2002). Uma vez atingido o xilema, as espécies vegetais dispõem de mecanismos capazes de excluir o excesso de $\mathrm{Na}$ das folhas (Silva et al., 2003; Akinci \& Simsek, 2004; Lacerda et al., 2004; Munns \& Tester, 2008).

Os mecanismos mais comumente utilizados para evitar o transporte excessivo de $\mathrm{Na}$ do xilema para as folhas são: retenção desse íon nas próprias células do caule; retenção de $\mathrm{Na}$ nos vacúolos das folhas mais velhas; e reciclagem xilema-floema, transferindo o excesso desse íon para as raízes (Lacombe et al., 2000; Watson et al., 2001; Cabot et al., 2005). Uma vez atingida a folha, o efeito tóxico do Na dependerá de alguns fatores, e os mais importantes são: capacidade de armazenamento nos vacúolos; manutenção de níveis elevados de $\mathrm{K}$ no citosol, resultando numa relação $\mathrm{K} / \mathrm{Na}$ elevada; e resistência tecidual à toxidez de $\mathrm{Na}$ (Munns, 2005; Munns \& Tester, 2008).

Segundo Silva et al. (2009a), as concentrações de $\mathrm{Na}$ nas folhas de plantas jovens de pinhão-manso aumentam intensamente já a partir de $25 \mathrm{mmol} \mathrm{L}^{-1}$ de Na na solução. Segundo esses autores, após 15 dias de exposição surgem os primeiros sintomas visuais de toxidez, e a partir de $50 \mathrm{mmol} \mathrm{L}^{-1}$ os sintomas tornam-se intensos, com manchas necróticas. Além disso, à medida que a concentração de Na no meio externo aumenta, a concentração de $\mathrm{K}$ nas folhas decresce abruptamente. Comparando esses resultados com os obtidos no presente estudo, é possível concluir que uma concentração maior de K na solução nutritiva, num tempo de exposição de oito dias, é capaz de reduzir a taxa de acumulação de $\mathrm{Na}$ e evitar o surgimento de sintomas visuais agudos (manchas necróticas) no limbo foliar (Figura 5).

Como ocorre em algumas outras espécies de glicófitas, concentrações adequadas de K podem atenuar parte dos efeitos adversos causados pelo excesso de $\mathrm{Na}$ em pinhão-manso. É interessante frisar que essa espécie, na fase de planta jovem, apresenta concentrações muito elevadas de $\mathrm{K}$ nas folhas, mesmo quando cultivada com níveis moderados desse nutriente $\left(3 \mathrm{mmol} \mathrm{L}^{-1}\right)$ na solução nutritiva. Contudo, são necessários mais estudos com plantas adultas e sob condições de campo para confirmar se o pinhão-manso é de fato muito exigente em $\mathrm{K}$ e se esse nutriente no solo em concentrações elevadas é capaz de atenuar os efeitos tóxicos causados pelo Na. Em síntese, plantas de pinhão-manso com $[\mathrm{K}]_{\text {ext }}$ em níveis adequados e expostas ao excesso de $\mathrm{NaCl}$ reduzem os efeitos adversos do excesso de $\mathrm{Na}$, possivelmente pela redução no transporte de $\mathrm{Na}$ no xilema e menor acumulação nas folhas. Esses dados sugerem que $[\mathrm{K}]_{\text {ext }}$ promovem fortemente a mitigação dos efeitos adversos do excesso de $\mathrm{Na}$ e redução desse íon em plantas de pinhão-manso.

\section{CONCLUSÕES}

1. Os íons $\mathrm{K}$ e Na apresentam forte antagonismo em termos de transporte e distribuição nos órgãos de plantas jovens de pinhão-manso.

2. Concentrações adequadas de K no meio externo são capazes de reduzir o transporte e os efeitos tóxicos do $\mathrm{Na}$ nas folhas. Inversamente, níveis elevados de $\mathrm{Na}$ são capazes de causar redução no transporte de $\mathrm{K}$.

3. O K apresenta seletividade várias vezes maior do que a de Na nos diversos órgãos de pinhão-manso.

\section{AGRADECIMENTOS}

Ao CNPq, INCTsal e Funcap, pelo suporte financeiro, e à Fazenda Tamanduá, situada em Santa Terezinha, Paraíba, pelo fornecimento de sementes selecionadas de pinhão-manso.

\section{LITERATURA CITADA}

ALVES, F.A.L.; FERREIRA-SILVA, S.L.; LIMA, J.P.S. \& SILVEIRA, J.A.G. Efeitos do $\mathrm{KCl}$ e $\mathrm{CaCl}_{2}$ na absorção e transporte de $\mathrm{Na}$ em cajueiro exposto a salinidade. Pesq. Agropec. Bras., 39:287-294, 2008. 
AKINCI, I.E. \& SIMSEK, M. Ameliorative effects of potassium and calcium on salinity sress in embryo culture of cucumber (Cucumis sativus L.). J. Biol. Sci., 4:361-365, 2004.

APSE, M. \& BLUMWALD, E. Na transport in plants. FEBS Letters, 581:2247-2254, 2007.

ASHLEY, M.K.; GRANT, M. \& GRABOV, A. Plant responses to potassium deficiencies: A role for potassium transport proteins. J. Exp. Bot., 57:425-436, 2006.

BEHERA, S.K. Evaluation of plant performance of Jatropha curcas L. under different agro-practices for optimizing biomass - A case study. Biomass Bioen., 34:30-41, 2010.

BUSCHMANN, P.H.; VAIDYANATHAN, R.; GASSMANN, W. \& SCHROEDER, J.I. Enhancement of Na uptake currents, time-dependent inward-rectifying $\mathrm{K}$ channel currents, and $\mathrm{K}$ channel transcripts by $\mathrm{K}$ starvation in wheat root cells. Plant Physiol., 122:1387-1397, 2000.

CABOT, C.; GARCIA, M.C. \& SIBOLE, J.V. Relation between xylem íon concentration and bean growth responses to shortterm salinisation in spring and summer. J. Plant Physiol., 162:327-334, 2005.

EBERT, G.; EBERLE, J.; ALI-DINAR, H. \& LUDDERS, P. Ameliorating effects of $\mathrm{Ca}\left(\mathrm{NO}_{3}\right)_{2}$ on growth, mineral uptake and photosynthesis of NaCl-stressed guava seedlings (Psidium guajava L.). Sci. Hortic., 93:125-135, 2002.

ESSAH, P.A.; DAVENPORT, R. \& TESTER, M. Sodium influx and accumulation in Arabidopsis. Plant Physiol., 133:307$318,2003$.

FLOWERS, T.J. Improving crop salt tolerance. J. Exp. Bot., 55:307-319, 2004.

GIERT, M. \& MASER, P. Plant potassium transporters - Involvement in K acquisition, redistribution and homeostasis. FEBS Letters, 581:2348-2356, 2007.

FERREIRA, R.G.; TAVORA, F.J.A.F. \& HERNANDEZ, F.F.F. Distribuição da matéria seca e composição química das raízes, caule e folhas de goiabeira submetida a estresse salino. Pesq. Agropec. Bras., 36:78-88, 2001.

FRANCIS, G.; EDINGER, R. \& BECKER, K. A concept for simultaneous wasteland reclamation, fuel production, and socioeconomic development in degraded areas in India. Need, potential and perspectives of Jatropha curcas. Nat. Res. Forum, 29:12-24, 2005.

HOAGLAND, D.R. \& ARNON, D.I. The water culture method for growing plants without soil. Berkeley, University of California, 1950. (Circular, 347)

JESCHKE, W.D. \& STELTER, W. Ionic relations of garden orache, Atriplex hortensis: Growth and ion distribution at moderate salinity and the function of bladder hair. J. Exp. Bot., 34:795-810, 1983.

LACERDA, C.F.; CAMBRAIA, J.; OLIVA, M.A. \& RUIZ, H.A. Influência do cálcio sobre o crescimento e solutos em plântulas de sorgo estressadas com cloreto de sódio. R. Bras. Ci. Solo, 28:289-295, 2004.
LACOMBE, B.; PILOT, G.; GAYMARD, F.; SENTENAC, H. \& THIBAUD, J.B. pH control of the plant outward-rectifying potassium channel SKOR. FEB S Letters, 466:351-354, 2000 .

MAATHIUS, F.J.M. \& AMTMANN, A. K Nutrition and $\mathrm{Na}$ toxicity: Bases of cellular K/Na ratios. Ann. Bot., 84:123133, 1999.

MENGEL, K. \& KIRKBY, E.A. Principles of plant nutrition. 5.ed. Dordrecht, 2001. 849p.

MUNNS, R. \& TESTER, M. Mechanisms of salinity tolerance. Ann. Rev. Plant Biol., 59:651-681, 2008.

MUNNS, R. Genes and salt tolerance: Bringing them together. New Phytol., 167:645-663, 2005.

MUNNS, R. Comparative physiology of salt and water stress. Plant, Cell Environ., 25:239-250, 2002.

RUBIO, F.; FLORES, P.; NAVARRO, J.M. \& MARTINEZ, V. Effects of $\mathrm{Ca}^{2+}, \mathrm{K}$ and cGMP on Na uptake in peppers plants. Plant Sci., 165:1049, 2003.

SATURNINO, H.M.; PACHECO, D.D.; KAKIDA, J.; TOMINAGA, N. \& GONÇALVES, N.P. Cultura do pinhão-manso (Jatropha curcas). Inf. Agropec., 26:44-78, 2005.

SCHURR, U. Xylem sap sampling - new approaches to an old topic. Trends Plant Sci., 3:293-298, 1998.

SILVA, E.N.; SILVEIRA, J.A.G.; RODRIGUES, C.R.F.; DUTRA, A.T.B. \& ARAGÃO, R.M. Acúmulo de íons e crescimento de pinhão-manso sob diferentes níveis de salinidade. R. Ci. Agron., 40:240-246, 2009a.

SILVA, E.N.; SILVEIRA, J.A.G.; RODRIGUES, C.R.F.; LIMA, C.S. \& VIEGAS, R.A. Contribuição de solutos orgânicos e inorgânicos no ajustamento osmótico de pinhão-manso submetido à salinidade. Pesq. Agropec. Bras., 44:437-445, 2009b.

SILVA, J.V.; LACERDA, C.F.; COSTA, P.H.A.; ENÉAS FILHO, J.; GOMES FILHO, E. \& PRISCO, J.T. Physiological responses of $\mathrm{NaCl}$ stressed cowpea plants grown in nutrient solution supplemented with $\mathrm{CaCl}_{2}$. Braz. J. Plant Physiol., 15:99-105, 2003.

VOIGT, E.L.; CAITANO, R.F.; MAIA, J.M.; FERREIRA-SILVA, S.L.; MACEDO, C.E.C. \& SILVEIRA, J.A.G. Involvement of cation channels and $\mathrm{NH}_{4}{ }^{+}$-sensitive $\mathrm{K}$ transporters in $\mathrm{Na}$ uptake by cowpea roots under salinity. Biol. Plant., 53:764-768, 2009.

WATSON, R.; PRITCHARD, J. \& MALONE, M. Direct measurement of sodium and potassium in the transpiration stream of salt-excluding and non-excluding varieties of wheat. J. Exp. Bot., 52:1873-1881, 2001.

WELBANK, P.J. The effects of competition with Agropyron repens and nitrogen and water on the nitrogen content of Impatiens parviflora. Ann. Bot., 26:361-373, 1962.

ZHU, J.K. Regulation of ion homeostasis under salt stress. Curr. Opin. Plant Biol., 6:441-445, 2003. 